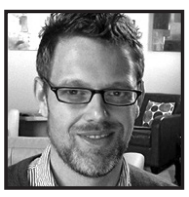

\title{
"Designerly" Ways of Reading: Insights From Reader Response in Drama for Enriching the " $A$ " in Language Arts
}

Treavor Bogard, University of Dayton

\section{ABSTRACT}

In this interpretive case study of reader response in drama, a drama troupe is the context for illuminating how young actors read in "designerly" ways; that is, how their reading processes facilitated constructive, solution-focused thinking in their development of characterizations. By examining the nature of reader response in the drama troupe, I hope to help educators understand how design thinking occurred as an aesthetic reading practice and consider ways in which design thinking can be cultivated in the language arts classroom. I argue that design thinking inspires the young to engage the imagination, practice teamwork, and take risks as they work to make their visions real. Perhaps most importantly, I contend that design thinking can help prepare the young for facing complex and highly ambiguous problems characteristic of 21st century participatory cultures.

\section{"Designerly" Ways of Reading: Insights From Reader Response in Drama for Enriching the " $A$ " in Language Arts}

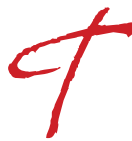

welve teenagers gather on the stage floor at the Civic Stage Theatre. Their first day of rehearsal, the empty stage activates imaginings of the characterizations they will embody and perform for hundreds of spectators. Clad in loose T-shirts and sweatpants, the young actors attune their bodies, voices, and minds to the creative space. Some stretch their bodies. Others chant a 
whimsical vocal warm-up, "If you saw a pink pug puppy playing ping pong with a pig, or a great grey goose a golfing with a goat..." The rest of the actors read their scripts with pencil and highlighter in hand. Suddenly, a loud voice reverberates throughout the theatre. All activity stops and, with rapt attention, they turn to face the production director who is now standing before them. With bravado, he conveys his expectations for the dramaturgical process they will soon undertake:

Every single one of you in this entire company is talented. That is how you got here. But I don't want to see a bunch of talented teenagers. I want to see characters. I want to see what you can do. I want you to take your character beyond what you would ever dream of.

I saw this invitation to design come to fruition during my three months of fieldwork at the Civic Stage Theatre (all names are pseudonyms) as part of a qualitative inquiry into literacy and the arts. Detached from everyday surroundings and concerns, the young actors released their imaginations and voice in a dynamic interplay of texts, readers, and bodies as they worked to make their characterizations real and concrete to audiences. Their intentional, active design of characters emerged from aesthetic readings of texts. They inferred meanings, attended to the details of dramatic composition, and demonstrated the "capacity to imagine what is not yet" (Greene, 1995a, p. 24). The "drama kids," as I came to call them, became critical consumers of text and engaged in many complex design decisions that shaped embodiment and performance.

As a former high school English teacher who now supports pre-service teachers in English Education, I could not help but notice that the drama kids' collaborative interactions around text evoked higher-order thinking, creativity, and problem solving. These processes, indicative of learning deeply, are often hoped for, but too seldom realized, in traditional language arts classrooms (Noguera, Darling-Hammond, \& Friedlaender, 2015). Yet, they were daily occurrences in the troupe's participatory culture. In light of my work as an English Language Arts (ELA) teacher educator, I wanted to know: What is the nature of reading response in drama? And what insights might be used to enrich literacy learning in language arts classrooms?

In this interpretive case study (Yin, 2003), I draw upon the theoretical perspectives of aesthetic literacy and design thinking to make sense of reading response situated in design practices. Specifically, I explain how the drama kids' aesthetic reading of dramatic texts attended to the sounds of language, the craft of writing, and the physical-psychological dimension of characters. I also describe the way they took 
risks as they worked to materialize their visions. I argue these engagements with texts revealed aspects of design thinking that were mediated by aesthetic literacy. In doing so, I offer a view of design thinking as a pathway to embodied knowing and higher thought. I conclude with implications for cultivating designerly ways of reading in the ELA classroom to promote constructive, solution-focused thinking and creative agency through the language arts.

\section{The Arts and Aesthetic Literacy}

Student learning in the arts is purposeful, active, sensual, and directly felt in the formation of the whole person; these attributes allow it to contribute to academic, social, and cognitive growth (Heath, 2001). Participatory cultures of arts organizations facilitate this personal growth. In these cultures, members have "low barriers to artistic expression, strong support for creating and sharing one's creations, informal mentorship, social connections with others, and the sense that their contributions matter" (Jenkins, Clinton, Purushotma, Robinson, \& Weigel, 2006, p. 7). Literacy practices in drama, for example, can mediate participatory culture via interactions around texts, embodied responses to literature, role-play, appropriation of mixed media, and other practices whereby literacy is a means of community involvement, performativity, and composing through multiple modalities (Bogard, 2016; Bogard, 2011).

Although classrooms are seldom sites for participatory cultures, arts integration is seen as one way of engaging students with content in a manner that produces some of the beneficial interactions of those cultures. Efforts to integrate the arts within ELA have often endeavored to cultivate students' aesthetic literacy through their responses to paintings, drawings, photography, new media, and performance (Athanases, 2008; Bomer, 2008). By aesthetic literacy, I mean direct encounters with the arts that elevate thought and perception and enhance awareness of the qualities and attributes of things. Aesthetic literacy entails "a skill of attending to, conceptualizing and communicating aesthetic qualities present in daily life" (Rautio \& Lanas, 2011, para. 6). It is the "capacity to observe, imagine, and engage with all that surrounds" (Gale, 2005 p. 9). Aesthetically literate people live consciously and read the world using all the senses; therefore, they experience things more directly. Being attuned to what resonates with them, they are aware of the particular elements in time and space that coalesce to evoke an aesthetic experience. Such higher-level cognitive functioning engages the reasoning mind and the sensing body. As a result, emotion, intellect, and embodiment are synergized in learning. When a direct encounter with art stimulates these sensations, learners experience a "resonating state and a readiness to perceive and act" (Gallagher \& Ihanainen, 2015, p. 17). 
Whether students are spectators or producers of art and whether the art is a painting, poem, literature, or live performance, they can learn ways of perceiving and attending that stimulate the emotion, senses, and intellect. A curriculum that integrates aesthetic literacy teaches students to align themselves to the thoughts, feelings, and meanings a work evokes. It also teaches them to become attuned to a text's features, such as its content, craft and structure, that elicit aesthetic responses (Greene, 1977; Rosenblatt, 1978). Students develop skill in listening to surroundings and responding imaginatively in ways that enable them to "transcend the common place and live more consciously" (Greene, 1983, p. 185). Such close reading and critical framing of texts grow students' capacity to "see, shape, and transform" (Greene, 1977, p. 18) and cultivate an aesthetic sensibility by which to judge their own compositions.

Aesthetic literacy, therefore, can inspire vision and voice, which learners use to respond to texts and to produce them. However, learners need a "designerly" way of thinking, common among composers and artists, to bring their visions into form and structure (Cross, 1996). This way of thinking is preoccupied with inventing something of value that does not yet exist, but fulfills a real-world need and creates an aesthetic experience for an end user or audience.

\section{Design as a Way of Thinking}

Whether they are actors, painters, poets, novelists, playwrights, or architects, creative people have ways of perceiving that stir their imaginations and compel them to put what they are seeing, thinking, and feeling into aesthetic form. As designers, they are driven by a sense of vision and a need to bring that vision into reality. According to Jones (1992), "Designers... are forever bound to treat as real that which exists only in an imagined future and have to specify ways in which the foreseen thing can be made to exist" (p. 10). A designerly way of thinking is solution-focused and guided by a vision that must be actively constructed by the designer. Thus, when articulating a vision, designers think and express ideas through a wide range of modalities such as images, sketches, models, demonstrations, and other creative expressions that transcend the written or oratory modes of communication. As a result, design thinking activates multiple cognitive domains-auditory, tactile, and visual.

In the execution of vision, which is a mental image of what the future will or could be, design thinking values emergence and possibility. Meinel and Leifer's (2011) four rules of design thinking reflect this sensibility: (a) design is a social practice (the human rule); (b) design thinkers must preserve ambiguity (the ambiguity rule); 
(c) all design is re-design (the re-design rule); and (d) designers must make ideas tangible (the tangibility rule). Collectively, these rules sustain creative agency and support the emergence of optimal outcomes. McKim (1980) describes the process of design thinking as the Express-Test-Cycle in which designers express an idea for a possible solution,then test the idea to determine what works and what does not. With each cycle, previously unrecognized properties are perceived. Attuned to emergent potential, designers build upon what works until an optimal solution is achieved or resources are depleted.

Design thinking is divergent in that it produces ideas that may appear "outside the box." Yet, it is also convergent in that it focuses on synthesizing ideas that most bear upon arriving at an optimal solution. While an idea opens new possibilities, what is used is determined by the parameters of the problem context and a felt sense of what is most appropriate for the collective vision. Throughout the process, design thinking keeps the audience or end user at the forefront of decision-making and therefore considers multiple perspectives and stakeholders in arriving at desired outcomes.

Within arts-based participatory cultures such as a drama troupe, what an artist envisions is often bound by what is ideal or most appealing for obtaining an optimal experience, effect, or response in spectators. That being so, design values "practicality, ingenuity, empathy, and a concern for appropriateness" (Cross, 1996, $\mathrm{p}$ 2). For example, in the dramaturgical process, the actors design and embody characterizations using their own creative agency. As a compositional practice, their design work entails the intentional arrangement of image, sound, gesture, gaze, print, music, speech, and other sign systems in light of their social purpose, intentions, context, and audience (Kress \& Van Leeuwen, 2001). They accomplish this, though, within the genre, style, and intent of the playwright's work, in alignment with the director's overall vision, and in consideration of expectations and response of the audience.

In this study, I use the drama troupe as a context for illuminating how young actors engage design thinking as part of their aesthetic literacy. By presenting this case, I hope to help educators understand aspects of design thinking as a reading practice and consider ways in which design thinking can be applied in traditional academic settings, particularly the language arts classroom. As I will show, design thinking can help students engage creative thinking, practice teamwork, and take responsibility for learning. Perhaps most importantly, design thinking can help prepare young people for the complex and highly ambiguous problems characteristic of 21st century participatory cultures. 


\section{Designerly Ways of Reading at the Civic Stage Theatre}

I came to know the drama kids during three months of fieldwork at the Civic Stage Theatre. Its Summer Youth Program provided tuition-free drama training to teenagers and cast them in full-scale stage productions of dramatic masterpieces. The troupe included 12 youth (four male and eight female, all between the ages of 13 and 18) and two adult male actors who served as mentors. From June until mid-August, they adhered to an intensive 10-week production schedule with rehearsals each weekday evening. On Saturdays, they attended workshops on set construction, lighting design, character makeup, and costumes.

Because this case study concerned reader response in the drama troupe, I aimed to capture the drama kids' lived-through experiences of reading dramatic texts as part of their character development process. Therefore, during my fieldwork, I collected the following data: two interviews with each of the drama kids about their reading processes, field notes, and video recordings of rehearsals that documented the dramaturgical process. My unit of analysis was the drama kids' aesthetic reading stance, which was their "thinking, feeling, and seeing" (Rosenblatt, 1980, p. 387) during reading. I transcribed the interviews and field notes and coded them using a constant comparative analysis procedure (Strauss \& Corbin, 1990), focusing on the thoughts, emotions, and associations the drama kids reported experiencing as they read their scripts.

Four features of aesthetic reading emerged from my analysis of the data set, and each had a central function in the drama kids' design of characterizations. These features were reading as design, attending to the sounds and craft of language, attending to embodiment, and taking risks in the actualization of vision. These elements enabled the drama kids to expand and synthesize their interpretation and embodiment of characterizations into a meaningful form. Incorporating excerpts from my field notes and interviews with the drama kids, I describe design thinking as it manifested in the aesthetic reading stance the drama kids took up as they developed characterizations, and I explain how this resulted in dramatic transformations of selves. In doing so, I aim to show design as a way of thinking that involves aesthetic literacy, strengthens creative agency, and holds promise for the teaching of the language arts.

\section{Reading as Design Work}

Greene (1977) writes, "Works of art only come into existence when a certain kind of heeding, noticing, or attending takes place" (p. 17). An aesthetic space emerges in which "learners align themselves to the possibility of learning, and then attune themselves to the specificities of their environment for learning" (Gallagher \& Ihanainen, 2015, p. 17). 
In this aesthetic space, we are both spectators of the thing perceived and authors of new imaginings evoked by our experience. For the drama kids, the design of a characterization gave them a reason to align themselves to learning about their character and attuning to the qualities and attributes of things they could appropriate into their vision of the role. Tuning in to their roles necessitated that they read the script with an aesthetic stance that helped them resonate with the experience, feelings, and physicality of their characters in the story world (Rosenblatt, 1978). To get to an aesthetic space of envisioning themselves in the role, the drama kids engaged in design thinking as a reading practice, which facilitated their constructive, solution-focused thinking during reading. For example, one of the drama kids, Wyndom, distinguished between "just normal reading" and reading with a design mindset:

Don't just read the lines and then try to go off it. Read it, read it out loud, and read it in your head. Don't read it as in just normal reading, think about the line, think about the meaning, and what you would be doing during that line.

By associating printed text with meaning, emotion, and embodied action, they learned to perceive and attend to aspects of the script that supported their design of the role. Because they used reading as a design practice, reading mediated the drama kids' aesthetic literacy.

Kress and Van Leeuwen (2001) have noted the active process of reading in mediating designs: "Reading involves active mental work. But that work is taking place on the levels of discourse and design, and it leads... to 'inward production'"' (p. 68). For the drama kids, this inward production involved the integration of mind-body during reading and attending to interacting modalities of characterization in their mind's eye. Wyndom continued:

You start with little things. Is your person handsy? Are they vocal? Their eyes? What part of the body do they use the most? I have big hands for my guy. And you kind of decide on an accent for the person. Yeah, just little things. What would that person do? Are they always like screaming a bit?

By attending to the different modalities of characterization during reading, the drama kids elevated their thought and perception. Reading as a design practice brought about an internal dialogue with the text and the application of an "initiating, constructing mind" (Greene, 1977, p. 23). Based on their ongoing analysis of the character, they uncovered emergent possibilities of themselves in the role and gradually synthesized the ideas that formed their creative vision. 


\section{Attuning to the Sounds and Craft of Language}

In the aesthetic space that emerged from reading as a design practice, the drama kids materialized visions of their characters by aligning and attuning themselves to the qualities and attributes they discerned in their close reading of the script. They began by focusing on the sounds and craft of language as a mode of design thinking. For example, several drama kids described hearing the sound of characters' voices as they read silently and tried approximating the inner voice they heard. Marty eloquently expressed this phenomenon:

Whenever I first read [the script], it is like when you are reading a novel. I don't know if it does for everyone, but each person has a certain sound. And when I read the script there will already be a way that person sounds in my head. And then I try to emulate what that was. And sometimes it just does not work at all, and sometimes it pans out beautifully. But where the sound comes from is based on what the initial feeling was.

Vocal variety, as a design choice, originated from their intuitive, felt sense (Perl, 1980) of the character in concert with a rational awareness of the vocal qualities most appropriate for their role. Importantly, Marty's attending to the sounds and voices of characters while reading was a "designerly" (Cross, 1996) way of thinking. A similar phenomenon has been noted among artists. John-Steiner (1985), who interviewed over 100 novelists, poets, actors, playwrights, sculptors, choreographers, and other creative professionals, found that these individuals used many "languages of thought" (p. 521) in combination. British author Margaret Drabble explained that, when writing novels, she relied on a "dramatic inner voice that spoke the lines and an active imagination that created visual images of the story" (as cited in John-Steiner, 1985, p. 521). Much like it is for artists, reading for the drama kids was a design practice that entailed many languages of thought that informed their embodiment and performance of the role. Their exploration of pitch, rate, accent, intonation, and other prosodic features during reading became some of the many languages of thought that they relied on to form their characterization.

When reading, the drama kids took their prosodic cues from sentence structures, punctuation, words, and phrases in the script to determine the tempo and rhythm of their characters' dialogue. Eric described how attuning himself to the structure of the printed dialogue enabled him to infer the internal state, vocal delivery, and embodiments for his character: 
Um, let's say he likes to speak in four and five word sentences. Then it feels like that person would speak very fast. Very quickly. And that lends a tension to the character. You can draw on just the fact that he has lots of very short sentences all in a row. You can create all kinds of physicality to that.

By aligning himself to his character and attuning to cues that signaled tonality, tempo, and inflection of the dialogue, Eric was able to imagine the psychological state of his character. As an aesthetic literacy process, this alignment and attunement enabled him to explore design choices that could convey to an audience the various internal states of his character. The young actors delighted in the ways inflections, rates, and accents shifted the text's meanings and helped to signify character type, social class, geography, and the character's state of mind. Often, generating an idea for one modality-such as the cadence of a character's voice-inspired other ideas for stance, gesture, and gaze, all of which added depth and complexity to the characterizations. By engaging aesthetic literacy, they began to see beyond the givens and conceptualize what could be possible in their roles. They then engaged in the design process to make their ideas a reality.

Conversely, reading as a design practice brought the young actors into an aesthetic space where they grew skill in perceiving the attributes of dramatic texts such as diction, speech patterns, and vocabulary. Because of their awareness of these text features, the drama kids associated good writing with subtext clues that might inform their physical and psychological embodiment of the role. Describing the process of getting ideas for a character, Kyle said:

It takes a lot of detailed going into the script and just reading it and reading it and trying to find little clues. And that is what good writing does-it gives you clues constantly of where the character is going and what they are wanting and what they are trying to achieve.

By engaging reading as a design practice for developing characterizations, Kyle and other young actors gained skill in identifying and analyzing aesthetic elements and in communicating their own aesthetic sensibilities and judgments of literary texts.

\section{Materializing Vision Through Embodiment}

By engaging reading as a design practice and translating their constructed meanings into embodied acts, the drama kids began to bring forth their vision into the world. They explored a wide range of embodiments until settling on those 
that felt the most natural for the role, and this process demanded they respond to real-time reactions from peers and the director. David described this as a collaboration in which the inner vision one formed from the words on the page is refined, shaped, and brought into the material world:

You are creating a character from words. You know, a fully fledged person with a voice and a gait and a style and a rhythm and an energy. None of that is going to be on a page. Words are on page. Sentences are on a page. Lines are on a page. But all the rest of that is all a collaboration. You have an idea. He has an idea. She has an idea.

Typical of design thinking, the collaboration David mentioned involved both divergent and convergent thinking regarding the legibility of character choices. The drama kids learned to ask of themselves and one another: "Does my embodiment look right? Does my voice sound right? Does what I am doing make sense in this context and situation?" By making their ideas tangible through embodied expression, the young actors now read and responded aesthetically to their bodies as texts, not just the printed page. Through ongoing revisions, they learned to re-see and self-assess their work by relying on felt sense as an evaluative response to the choices they made.

In order to inspire confidence and ownership of their roles, the director posed questions that framed an aesthetic space around their characterization. In that space, he helped the students attune to the script and notice various qualities of their role that could inspire their character design choices. Doing so helped them link embodied action with intention and textual evidence from the script. Their director explained:

If a kid comes up to me and says, "I was thinking of trying this," I will say, "Okay, why? Tell me why you are thinking that. Where is that coming from?" What it does is it forces them to know the story. It forces them to get more deeply involved with their characters. And I think they just have a better appreciation for their work instead of my work.

In addition to increasing the drama kids' creative agency, the director's collaborations with the young actors illustrated design thinking as a social process that facilitated divergent thinking in order to express and test ideas for characters. As considerations of form and structure arose, though, their structuring of embodiment exemplified convergent thinking as they worked to synthesize mind, body, and voice to achieve a believable characterization. This process of expressing, testing, and refining embodied 
reader responses required taking risks and letting go of anxieties over correctness that had pervaded many of their school learning experiences. Therefore, they needed to feel safe taking creative risks to extend their embodiment and performance far beyond their usual disposition.

\section{Risk-Taking in Embodied Reader Response}

Greene (1995a) contends that the role of imagination is "... to awaken, to disclose the ordinarily unseen, unheard, and unexpected" (p. 28). In the ephemeral maybes of design, it mattered that the drama kids had an interpretation, but also that they were open to the unknown, emergent potential of themselves in the role and open to exploratory embodiments. Ambidextrous thinking - "thinking outside the box"was essential to innovation and involved "...the spontaneous and egoless act of invention by which individuals improve themselves and their world through expression and learning" (Rolf A. Faste Foundation for Design Creativity, n.d., para. 1).

To set a precedence for the risk-taking inherent in ambidextrous thinking, the director encouraged the drama kids to play different levels of physicality and prompted them to determine what part of the body a character leads with: the chest, head, groin, and so on. They worked at cohering embodiments into culturally recognizable character types. At times, these designs deviated from normative expectations; outside the theatre context, they would have placed the young people in socially vulnerable positions andidentities. Yet, this also allowed them to explore texts, identities, and embodiments without experiencing a threat to identity. For example, Daryn was cast as two characters of different gender in the same production; one character was a mother and the other a male preacher. His design of gesture in these roles conveyed maternity for one character and spirituality for the other. He played the mother's gestures lower and nurturing, as if always kneeling to caress, gather, and protect, while he played the preacher's gestures toward the heart and heavens. In these ways, the choice of embodiments registered archetypal images and discourses and required the young people to take public and social risks in inhabiting diverse others.

Typical of design processes, character choices, when embodied, were subject to real-time peer reactions and director feedback in a test-express cycle (McKim, 1980). In this process of materializing vision, the actors let go of choices that did not produce a desired effect, kept aspects of a choice that worked, and built again from that point. Initially, however, the group spectacle of embodiment and performance demanded a level of risk-taking that made some drama kids apprehensive.This was especially true of Daryn. In the early rehearsals, he was reluctant exploring gendered embodiments 
that deviated from his shy manner. Fearful of being perceived too outlandish, he held back his performance whenever the troupe focused on him. For example, in his role as the preacher, he played scenes addressing a church congregation in the oratorical style of an enraged evangelist. Daryn floundered with authoritative gestures and with getting his voice older and deeper. As he stood up high behind a pulpit, he looked down on a congregation of his peers who cheered and applauded the character choices he made that broke from his quiet disposition, but heckled him when he showed sudden reluctance to get bigger. In fact, their responses affirmed embodiments that showed emergence of his characterization, but Daryn did not yet know how to interpret or play to his peers' reactions, so he shut down. Afterward, Daryn complained to the director, "I feel like everybody is on me." He gestured back at the empty chairs where the congregation had been. "Some of that is just you," said the director. "Some of that is an excuse for you not to work harder. We do that when we feel we are going out on a limb or we are visiting virgin territory. We make excuses not to go there." Quiet and sensitive youth like Daryn, whose search for voice drew them to the stage, were pushed to go further with their characters and put their bodies on the line. In Daryn's case, that pushing developed into an ethic of courage and hard work. Gradually, he learned to take risks bringing his vision into form, which required a readiness to express his ideas through embodiments that were tested and refined through peer reactions and the director's feedback.

In the troupe's participatory culture, learning was located in the doing, and nothing had to work the first time. Indicative of design thinking, the troupe regarded choices that did not work as essential to discovering what might work, which opened new possibilities for growing characterizations. As a result, risk-taking was not merely encouraged; it was a necessary condition for bringing their visions into embodiment. The director said:

I tell them, "It is okay to fail. It is okay to do something totally stupid and laugh about it. And who knows? Maybe something stupid is the beginning of a new creation." We laugh about it but say, "But wait, there is a kernel that I really like," so I welcome it in the rehearsal hall and I think many of them take to it.

Youth learned not to fret much over how they were perceived for the choices they made to grow their characterization. They became comfortable dealing with the ambiguities of complex problems whose solutions are not found or ready-made, but constructed through divergent and convergent thinking, synthesis, and analysis. Gradually, as all these processes came together, a clear path forward appeared. 
Inherent to this design process, risk-taking created an environment in which the drama kids felt comfortable shedding social fronts and loosening the grip of established norms and relations. And design thinking cultivated an aesthetic space that directly engaged the body, mind, and senses, heightening their readiness to perceive and respond anew. As a result, both texts and selves were continually reimagined and re-designed throughout the dramaturgical process.

\section{Dramatic Transformations of Selves}

I have so far described reading as a design practice that facilitated vision, embodiment, and risk-taking in the performance of characterizations. In the aesthetic space that emerged, the drama kids described releasing diverse aspects of self that they ordinarily hid. Deborah explained:

I just let it all hang out. I mean it all hung out. You know, it was just really fun. I feel like that's more of myself, but I don't always let that part show... I kind of just said whatever I thought at that moment. You know, I mean whatever it was, I felt like my true self came out a lot more. I could just say it.

Brought forth through the design process, one of the outcomes of aesthetic literacy was enlivening in the drama kids a "resonating state" and a "readiness to perceive and act" (Gallagher, \& Ihanainen, 2015, p. 17). In their readiness to respond imaginatively, they gave voice to aspects of themselves that they ordinarily silenced and in doing so temporarily suspended normative expectations of themselves and others. Identities typically invisible or marginalized in mainstream contexts became heard and seen among the cast of characters at play in the troupe's participatory culture. By materializing the imagination, they made a space for themselves where they enjoyed greater coherence between inner states and the outer presentation of selves than they usually experienced.

Additionally, reading and embodying difference opened a space of self-authoring for some drama kids that resulted in a more nuanced view of themselves and other people. Because the actors related to diverse characters and peers socially, emotionally, physically, and cognitively throughout the dramaturgical process, some drama kids began questioning their world view. Jason said:

Theatre is a safe way to question the world because it is not a rebellious, dangerous sort of "oh my parents have been lying to me all through life." No, it is sort of "Okay, but why did they say that to me?" It is just-it definitely will stretch you in different ways. 
By coming into contact with a multiplicity of identities and personas, people can enter into an internal dialogue that questions the dogma of authoritative discourses (Greene, 1995b), and this happened for some of the drama kids. The plurality of voices, bodies, and points of view that circulated in the design of characterizations invited them into a space of self-authoring where they could question normalizing discourses and contemplate the possibility of choosing for themselves the kinds of persons they wanted to be in the world.

Finally, design thinking and aesthetic literacy in drama transformed the drama kids' views of learning. On the closing night of the production, the director asked the troupe members to reflect on their creative process. Ben said, "For me, developing my character was not only an acting experience, but also a way in which I learned how to learn." And Michael commented, "Here in the theatre you just like totally expand everything, but at school we have to work inside the guidelines." As a result of engaging the collaborative process of bringing textual interpretations into embodied form, they associated learning with use of the imagination, critical thinking, and acting on possibilities. These designerly ways of reading and thinking are necessary for solving messy, ill-structured problems, but stood apart from their experiences of school-based learning as "rational, linear, systematic, and controlling" (Heron, 1996, p. 45). By reading, perceiving, attending, and using their bodies in motion, the drama kids began to bring severed parts of themselves together into a more self-actualized whole, a work of art.

\section{Insights for Design Thinking and Aesthetic Literacy in ELA}

Greene (1995b), staunch advocate for the arts in education, cautions: "Boredom and a sense of futility are among the worst obstacles to learning" (p. 149). My inquiry into reader response in drama, particularly reading as a design practice, has made me mindful of ways educators can combat these obstacles by inviting students to perceive, relate to, and respond to academic content in ways that can cultivate presence of mind, energy, focus, and the use of the imagination. I offer four ways language arts educators can cultivate design thinking in the classroom to inspire aesthetic literacy.

Situate reading in design. Situating reading in a design task can provide a purpose for attending to the unique attributes and qualities of the thing perceived. Aesthetic space can emerge when attending to the craft features of a short story, a stanza from a poem, a quote, song, staging, or any composition. Yet, among the most promising ways to elevate perception of text features is situating reading within a design task that gets young people interacting with texts and composing works they 
care about. If we want students to deconstruct and critically examine texts for the discourses they reproduce, then students need experiences making design decisions in consideration of their content, purpose, and audience. An aesthetic space can then open for reflecting on the discourses that they, as designers, are reproducing.

Increase modalities for generating and representing meaning. A vision is more likely to emerge when students have opportunities to compose through multiple sign systems. If we expect students to generate multiple perspectives and interpretations of literature, then they will benefit from more modalities than printed text alone to focus their attention, make connections, and deepen their responses. When allowed to produce meanings through multiple sign systems and to work in many languages of thought, students who struggle with verbocentric literacy often experience gains in volition, achievement, and a sense of purpose in academic literacy (Siegel, 2006). With more languages of thought with which to create meaning, they may be more inclined to use ambidextrous thinking and work through the challenges of ambiguous problem situations.

Create a holding environment for developing and actualizing vision. Sustained perception and attention must be taught and modeled, then directed into a space that can give shape and form to the ideas perceived. Aesthetic space can grow by being aware of one's senses and emotions, then directing those energies into a holding environment, a space for incubating ideas and cohering them into some embryonic form until they are ready to hatch. For the actor this is the rehearsal space; for the artist it is the sketchbook; and for the writer it is the writer's notebook. In such spaces, people are free to explore ideas, find patterns, make connections, and develop a vision. While the process begins with a lone, focused mind, what is materialized is socially mediated and inspired by collective interest or endeavor. Being surrounded by other artists, writers, and performers arouses creative sensibilities, instincts, and potentiality. In that safe space of possibility, students generate desire and momentum for bringing voice to vision and vision into form.

Position students as designers. Young people take up a range of subject positions such as active producers, creators, directors, editors, composers, writers, and even actors when they are engaged in multimodal composition. Considerations of design, of seeing how pieces fit together, and testing the affordances of potential modes in shaping meaning are ways they can learn to perceive and attend to texts as designers. Producing and responding to a text can be integrated with consideration of its design, of how its meanings could be shaped, embodied, and rendered anew. In the process, young people become positioned as designers of text, rather than passive consumers of print and image. 
Finally, educators might help young people discern how the author's purpose and audience influence the choice of modalities that comprise a text. Such conversations, particularly in students' own compositions, may grow an aesthetic awareness of how one's modal choices affect a text's meanings. The sense of self as designer may grow by asking students to explain their choices, the emergent decisions that led to their final product, and by encouraging risk-taking inherent in the formation of texts and authors. Such conversations create an aesthetic space of inquiry into the techniques, forms, and themes of students' compositions, and the texts that inspire them. A more nuanced perspective of the creative process and a work's meanings can elevate perceptions of self as a creative agent capable of shaping and forming the material world.

\section{Dare to See Beyond the Givens}

"I want to see what you can do. I want you to take your character beyond what you would ever dream of."

- Director, Civic Stage Theatre

Bringing insights from the stage to the ELA classroom demonstrates the potential of design thinking for actualizing aesthetic literacy in ways that can heighten awareness of texts, ourselves, and the world. The crusty terrain of standards, curriculum, and assessment may be looked upon with new perspective, opening up possibilities for instilling creative agency and voice in learning that is active, not inert or uninspired. Doing so is imperative at a time when pathways to aesthetic literacy are too often disregarded in national academic standards, benchmarks, pacing guides, and accountability measures. As a self-actualizing step toward fashioning a higher reality, we might "...move the young to notice more, to attend more carefully, to express their visions, to choose themselves" (Greene, 1977, p. 20). We might, like the drama kids, dare to embrace design thinking and aesthetic literacy as an orientation toward learning. In the doing, we might perceive anew what we can do, then take ourselves-our teaching, our character-beyond what we imagined was possible. 


\section{References}

Athanases, S. Z. (2008). Theatre and theory partnered through ethnographic study. In J. Flood, S. B. Heath, \& D. Lapp (Eds.), Handbook of research on teaching literacy through the communicative and visual arts (Vol. 2, pp. 119-127). New York: Lawrence Erlbaum Associates.

Bogard, T. (2011). Serious play: Exploring literacies and masculinities in drama companies for young adults (Doctoral dissertation). Retrieved from https:// repositories.lib.utexas.edu/handle/2152/ ETD-UT-2010-05-825

Bogard, T. (2016). Stepping out with the fop: Literacies of embodiment and becoming in youth drama. In Thomas, P., Takayoshi, P. (Eds.), Literacy in practice: Writing in private, public, and working lives (Chapter 9, pp. 118-133). New York: Routledge.

Bomer, R. (2008). Literacy classrooms: Making minds out of multimodal material. In J. Flood, S. B. Heath, \& D. Lapp (Eds.), Research on teaching literacy through the communicative and visual arts (Vol. 2, pp. 353-359). New York: Lawrence Erlbaum Associates.

Cross, N. (1996). Designerly ways of knowing. London: Springer-Verlag.

Gale, R. (2005). Aesthetic literacy and the "living of lyrical moments". Journal of Cognitive Affective Learning, 2(1), 1-9.

Gallagher, M. S., \& Ihanainen, P. (2015). Aesthetic literacy: Observable phenomena and pedagogical applications for mobile lifelong learning (MLLL). European Journal of Open, Distance and E-Learning, 18(1), 15-33.

Greene, M. (1977). Imagination and aesthetic literacy. Art Education, 30(6), 14-20.

Greene, M. (1983). Landscapes of learning. New York: Teachers College Press.

Greene, M. (1995a). Imagination, breakthroughs, and the unexpected. In Releasing the imagination (pp. 17-31). San Francisco: Jossey-Bass.

Greene, M. (1995b). Texts and margins. In Releasing the imagination (pp. 134-154). San Francisco: Jossey-Bass.
Heath, S. B. (2001). Three's not a crowd: Plans, roles, and focus in the arts. Educational Researcher, 30(7), 10-17.

Heron, J. (1996). Co-operative inquiry: Research into the human condition. London: SAGE.

Jenkins, H., Clinton, K., Purushotma, R., Robinson, A., J., \& Weigel, M. (2006). Confronting the challenges of participatory culture: Media education for the 21st Century. Chicago: The MacArthur Foundation.

John-Steiner, V. (1985). Notebooks: Explorations of thinking. Albuquerque: University of New Mexico Press.

Jones, J. C. (1992). Design methods. New York: John Wiley \& Sons.

Kress, G. R., \& Van Leeuwen, T. (2001). Multimodal discourse: The modes and media of contemporary communication. London: Arnold.

McKim, R. H. (1980). Experiences in visual thinking. Salt Lake City: Brooks/Cole Publishing Company.

Meinel, C., \& Leifer, L. (2011). Design thinking research. In C. Meinel, L. Leifer, \& H. Plattner (Eds.), Design thinking: Understand, improve, apply (pp. xiii-xxi). Berlin: Springer-Verlag

Noguera, P., Darling-Hammond, L., \& Friedlaender, D. (2015). Equal opportunity for deeper learning. Retrieved from http://www.jff.org/sites/ default/files/publications/materials/EqualOpportunity-for-Deeper-Learning-100115a. pdf

Perl, S. (1980). Understanding composing. College Composition and Communication, 31(4), 363-369.

Rautio, P., \& Lanas, M. (2011). Aesthetic Literacy in Relanguaging Rural Everyday Life as GoodEnough. Paper presented at the Annual Meeting of AERA (American Educational Research Association), Round table: Sensing Place: Embodiment and Aesthetics in Ecological Inquiry. April 8-12, 2011, New Orleans, Louisiana, US. 
Rolf A. Faste Foundation for Design Creativity. (n.d.). AmbiThink: An open innovation platform. Retrieved from http://www.ambidex trousthinking.org

Rosenblatt, L. M. (1978). The reader, the text, the poem: The transactional theory of the literary work. Carbondale: Southern Illinois University Press.

Rosenblatt, L. M. (1980). What facts does this poem teach you? Language Arts, 57, 386-394.
Siegel, M. (2006). Rereading the signs: Multimodal transformations in the field of literacy education. Language Arts, 84(1), 65-77.

Strauss, A., \& Corbin, J. (1990). Basics of qualitative research: Grounded theory procedures and techniques. London: Sage Publications.

Yin, R. K. (2003). Case study research: Design and methods (3 ed., Vol. 5). Thousand Oaks: Sage.

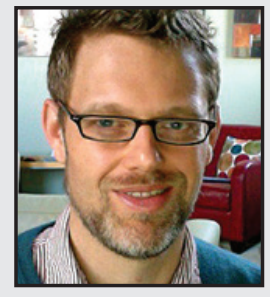

Treavor Bogard, PhD, is Assistant Professor in the Department of Teacher Education at the University of Dayton, where he teaches courses in reading and language arts methods. His scholarship concerns the social, cognitive, affective, and environmental conditions that facilitate deep learning and positive identity development in contexts such as literacy workshop, online educational gaming, and youth drama. His latest study, "Literacies of Embodiment and Becoming in Youth Drama," appears in Literacy in Practice: Writing in Private, Public, and Working Lives (Routledge, 2016). He is co-author of recent studies published in Educational Technology Research and Development and The Elementary School Journal. 